\title{
LABORATORY PROJECTS USING INQUIRY-BASED LEARNING: AN APPLICATION TO A PRACTICAL INORGANIC COURSE
}

\section{José G. Carriazo}

Departamento de Química, Facultad de Ciencias, Universidad Nacional de Colombia, Ciudad Universitaria, Carrera 30 No. 45-03, Bogotá, Colombia

Recebido em 23/10/10; aceito em 24/1/11; publicado na web em 25/3/11

\begin{abstract}
This paper reports how laboratory projects (LP) coupled to inquiry-based learning (IBL) were implemented in a practical inorganic chemistry course. Several coordination compounds have been successfully synthesised by students according to the proposed topics by the LP-IBL junction, and the chemistry of a number of metals has been studied. Qualitative data were collected from written reports, oral presentations, lab-notebook reviews and personal discussions with the students through an experimental course with undergraduate second-year students at the Universidad Nacional de Colombia during the last 5 years. Positive skills production was observed by combining LP and IBL. Conceptual, practical, interpretational, constructional (questions, explanations, hypotheses), communicational, environmental and application abilities were revealed by the students throughout the experimental course.
\end{abstract}

Keywords: inquiry-based learning; inorganic laboratory; chemical education.

\section{INTRODUCTION}

There is growing recognition that recent accounts by cognitive scientists of how learners learn pose challenges for current understanding of conceptual learning in science, and they emphasise the fundamental role of context, perception, identity, feelings, embodiment, metaphor, story-telling, and pattern completion in learning. ${ }^{1}$ Nevertheless, in spite of enormous efforts the learning in science, and so the teaching of science, go on being very complex events. Several approaches have been proposed to teach science, ${ }^{2,3}$ in which the development of critical thinking accompanied by the ability to search scientific literature, interpret technical information, work in team and generate explanations and hypotheses about scientific phenomena, concepts or procedures has been the teaching process' major aim. ${ }^{4-6}$ Different styles have been adopted for teaching science in the laboratory; ${ }^{6,7}$ however, the cooperative construction of knowledge may perhaps be better reached through developing mini-projects.

The general term "project" (or mini-project) in science education refers to the practical work in which the students spend several weeks on (for example more than 4-5 weeks with 3-5 h laboratory sessions) for accomplishing a proposed topic..$^{3,8,9}$ The project-based learning allows introducing the students to a scientific literature context, which exposes them to the interdisciplinary nature of modern chemical research. ${ }^{10}$ On the other hand, inquiry-based learning strategies represent a teaching methodology founded on constructivism involving a problem-solving approach, ${ }^{6}$ and represent one of the best methods for understanding the nature of science (a term used for describing how science is done and how scientific knowledge is constructed). ${ }^{9,11-14}$

Many papers have recently suggested the use of inquiry-based learning (IBL) methodology for lab work (inquiry-based labs), indicating students and teachers' features, advantages, opinions and concepts as well as showing its implementation as central strategy in several science education reforms. ${ }^{9,11,15-17}$ IBL currently constitutes a line of research in science education in which a teacher proposes

*e-mail: jcarriazog@unal.edu.co developing curricular contents through a series of activities and "problematical situations" arising from questions of interest being given to the students, thereby encouraging them to reconstruct their own knowledge. Such open-ended instructional style comes within the context of IBL in which practical work is developed by a laboratory-investigative approach. Questions raised during the course of projects when using this experimental educational style represent a good approach to scientific work; they lead to theoretical concepts being related to some practical applications and help to transfer classroom-acquired knowledge to everyday contexts, ${ }^{12}$ an interesting and essential aspect for connecting the school knowledge with students' real-life. ${ }^{18}$

Students act like "researchers" (in teacher-orientated activities) in the IBL open-ended style, similar to the scientific work, and must not have lab-guidelines (cookbook) but should construct or adapt their own procedures using chemistry literature. The student must define a particular problem, construct hypotheses founded on scientific literature, design experiments, obtain coherent results and show his ability to analyse results.

However, such aspects may not be easily covered at any educational level but they may be included in an advanced stage of implementing this learning model in which the learner (in the case of science students and particularly chemistry students) requires some typical experimental competences to make, adjust, manipulate and correctly direct chemistry experiments towards verifying proposed hypotheses. A teacher acts as a research director in this learning model, managing the work and giving advice, generating pertinent questions, giving coherent and opportune explanations, suggesting and facilitating the implementation of techniques and methods of work. The teacher also discusses results with the students, stimulating oral and written reports (seminars, poster sessions and final reports in scientific paper form).

This paper has thus been aimed at showing an interesting experience regarding implementing an experimental inorganic course by using a connection between laboratory projects (LP) pedagogical strategy and the IBL style for enhancing chemistry students' learning. 


\section{METHODOLOGY}

A qualitative methodology was followed for this work. The data and observations discussed here were collected from the author's experience acquired just by developing an experimental inorganic chemistry course (second year undergraduate students) using miniproject methodology and IBL laboratory style during the last 5 years at the Universidad Nacional de Colombia in Bogotá (written reports, oral presentations, personal discussions with students and lab-notebook were analysed). Detailed instructions on implementing this methodology and orientating questions for discussion have been published elsewhere for a specific case. ${ }^{4}$

About twenty students were divided into ten groups of two people in each course; each group carried out a different topic in the field of inorganic chemistry synthesis. The students (motivated by an initial preliminary lecture given by the teacher) chose a synthesis topic and then prepared a small project based on a set of initial questions proposed by the teacher. The mini-project had to be composed of a small state of the art (literature review), a proposal for synthesis procedure and characterization (chemical and spectroscopic techniques) of the synthesised compounds. ${ }^{4}$ The teacher (acting as referee) had to review and discuss/correct the written project for each two-student group before the work was carried out. A lot of attention had to be given to the students' writing style at this point because they should acquire scientific writing abilities. ${ }^{4,19,20}$

A part of qualitative information was acquired from oral presentations using the following format (Figure 1).

\begin{tabular}{|c|c|c|c|}
\hline \multicolumn{4}{|c|}{$\begin{array}{l}\text { Universidad Nacional de Colombia } \\
\text { Science Faculty, Chemistry Department, Bogotá-D.C. } \\
\text { Students:__ }\end{array}$} \\
\hline \multirow{4}{*}{$\begin{array}{l}\text { Form and } \\
\text { presentation }\end{array}$} & & Achievements & Mistakes \\
\hline & Communication: Oral skill & & \\
\hline & Conceptual approach & & \\
\hline & Nomenclature use & & \\
\hline \multirow{5}{*}{$\begin{array}{l}\text { Synthesis } \\
\text { procedure }\end{array}$} & Hypothesis construction & & \\
\hline & Thermodynamic and kinetics & & \\
\hline & Stoichiometric approach & & \\
\hline & Purification techniques & & \\
\hline & Final product obtained & & \\
\hline \multirow{4}{*}{$\begin{array}{l}\text { Characterisation } \\
\text { techniques }\end{array}$} & Chemical analysis & & \\
\hline & Magnetic susceptibility & & \\
\hline & Spectroscopy & & \\
\hline & Another techniques & & \\
\hline \multirow{2}{*}{$\begin{array}{l}\text { Spectroscopy } \\
\text { principles }\end{array}$} & Theory and concepts & & \\
\hline & Application & & \\
\hline \multirow{2}{*}{$\begin{array}{l}\text { Coordination } \\
\text { chemistry }\end{array}$} & Bonding theories & & \\
\hline & Structural approach & & \\
\hline \multirow{2}{*}{$\begin{array}{lr}\text { Context and } \\
\text { Application of } \\
\text { compounds }\end{array}$} & Chemical importance & & \\
\hline & \begin{tabular}{|l} 
Social and industrial \\
relevance
\end{tabular} & & \\
\hline
\end{tabular}

Figure 1. Format designed for evaluation of seminaries (oral presentation) on the work of students. This format let to obtain qualitative information for characterising LP-IBL application

\section{RESULTS AND DISCUSSION}

The two-student groups synthesised several inorganic compounds ( 2 or 3 compounds per group) as shown in Tables 1 and 2. Each group socialised its results via an oral presentation (like a scientific meeting) and a final report written in form of a scientific paper (according to a format from The Royal Society of Chemistry).
Table 1. Titles of the like-paper written reports received during the last academic semester's laboratory course

\begin{tabular}{|c|c|}
\hline Work number & Title of report \\
\hline 1 & Synthesis and characterisation of nickel(II) compounds \\
\hline 2 & $\begin{array}{l}\text { Preparing potassium bisoxalatocuprate and } \\
\text { acetylacetonatocopper(II) }\end{array}$ \\
\hline 3 & Iron(III) complexes: synthesis and characterisation \\
\hline 4 & Investigating vanadium coordination compounds \\
\hline 5 & $\begin{array}{l}\text { Synthesis and characterisation of cobalt-coordination } \\
\text { compounds }\end{array}$ \\
\hline 6 & Tin(IV)-coordination compounds \\
\hline 7 & $\begin{array}{l}\text { Synthesis of sulfatotris(thiourea)zinc(II) and a Schiff base } \\
\text { complex. }\end{array}$ \\
\hline 8 & Studying chromium (III) complexes \\
\hline 9 & The chemistry of lead compounds \\
\hline 10 & $\begin{array}{l}\text { Preparing, characterising and applying manganese } \\
\text { complexes }\end{array}$ \\
\hline
\end{tabular}

Table 1 gives interesting topics concerning inorganic chemistry which let students establish a broad discussion on matters such as the chemistry of metals, their coordination and periodicity. The synthesised compounds, the main characterisation techniques used in each lab work and the general abilities observed through the laboratory sessions, discussions and reports are shown in Table 2. It is worth highlighting the use of advanced techniques such as X-ray diffraction (XRD) and infrared (IR) spectroscopy as well as ordinary chemistry techniques. Good use of techniques for characterising compounds was observed in all cases and students' cooperation in understanding concepts and applications was clearly detected. Prior knowledge of the students was important here (it is significant to highlight that a considerable body of research has demonstrated that domain-specific prior knowledge is the best predictor of student achievement in various academic content fields). ${ }^{21}$ In addition, frequent questions and explanations about IR and XRD results (discussions between students and teacher) were recorded.

The ability types shown in Table 2 were observed. A group of conceptual abilities regarding coordination chemistry principles, nomenclature, stoichiometry, inorganic synthesis techniques, controlling redox reactions, periodicity, theoretical foundations of characterisation techniques, etc. could be revealed by the students throughout the experimental course and be confirmed by reports and oral presentations. A second group of practical abilities including lab unit operations, applying purification methods and characterisation techniques was also observed. A third group of interpretation abilities was observed when students were engaged in scientific literature selection, compilation and interpretation. A fourth group of construction abilities involving explanations of phenomena and building scientific questions and hypotheses was detected (having more strength in some students than others).

Communication skills represented an important type of ability which was developed in almost all students. Developing writing and oral skills was somewhat difficult and some scientific and language mistakes were frequently observed in reports and oral presentations of several students due to difficulty in coherently and concisely expressing ideas. A group of environmental and application abilities was also found; such skills included some industrial applications for most synthesised compounds as motivation for preparing them according to their technological, scientific and social impact (meaningful learning, and science, technology and society focusing). ${ }^{22,23}$ Environmental awareness abilities were revealed in all students when dealing with synthesis by controlling the quantities of reagents to avoid subsequent 
Table 2. Synthesised compounds, the main techniques used for characterising them and general abilities observed in the students through written reports and oral presentations

\begin{tabular}{|c|c|c|c|}
\hline Report & Synthesised compounds & Characterisation techniques* & General abilities observed \\
\hline 1 & $\begin{array}{l}\text { Tris(etylenediamine)nickel(II) chloride. } \\
\text { Acetylacetonatodiaqua(1,3-propanediamine)nickel(II) perchlorate. }\end{array}$ & IR, XRD, UV-Vis, MS, ST, VT, MP. & \multirow{10}{*}{$\begin{array}{l}\text { Coordination chemistry principles, } \\
\text { bonding theories, inorganic synthesis } \\
\text { techniques, use of Pourbaix's diagrams, } \\
\text { compounds purification, stoichiometry } \\
\text { principles, chemical products safety, } \\
\text { treatment of inorganic residues, inor- } \\
\text { ganic nomenclature, periodicity, IR } \\
\text { spectroscopy principles, crystal struc- } \\
\text { ture determination and XRD, literature } \\
\text { search, interpreting chemical texts, } \\
\text { constructing questions, formulating } \\
\text { hypotheses, writing skills, identifying } \\
\text { industrial and environmental applications }\end{array}$} \\
\hline 2 & $\begin{array}{l}\text { Potassium bisoxalatocuprate(II). } \\
\text { Acetylacetonatocopper(II). }\end{array}$ & IR, XRD, MS, ST, COD, HW. & \\
\hline 3 & $\begin{array}{l}\text { Potassium tris(oxalato)ferrate(III) trihydrate. } \\
\text { Ferrocene. }\end{array}$ & IR, XRD, MS, VT, HW. & \\
\hline 4 & $\begin{array}{l}\text { Bis(acetylacetonato)oxovanadium(IV). } \\
\text { Oxovanadium(IV) salen. }\end{array}$ & ST, MS, IR, OM, MP, XRD. & \\
\hline 5 & $\begin{array}{l}\text { Pentaamminechlorocobalt(II) chloride. } \\
\text { Dinosar)cobalt(III) chloride. }\end{array}$ & IR, MS, VT, UV-Vis, Kj, IE. & \\
\hline 6 & $\begin{array}{l}\text { Ammonium hexachlorostannate(IV). } \\
\text { Tetrachloro(ethylenediamine)tin(IV). }\end{array}$ & MS, IR, XRD, ST. & \\
\hline 7 & $\begin{array}{l}\text { Sulfatotris(thiourea)zinc(II). } \\
\text { Bis(salicylaldehyde)ethylenediiminezinc(II). }\end{array}$ & IR, XRD, ST, UV-Vis, MP. & \\
\hline 8 & $\begin{array}{l}\text { Pentaacuachlorochromium(III) chloride. } \\
\text { Tris(1,10-phenanthroline)chromium(III) hexafluorophosphate. }\end{array}$ & UV-Vis, ST, XRD, IE. & \\
\hline 9 & $\begin{array}{l}\text { Ammonium hexachloroplumbate(IV). } \\
\text { 1,4-benzenedicarboxyl)lead(II). }\end{array}$ & UV-Vis, MP, IR, XRD, MS. & \\
\hline 10 & $\begin{array}{l}\text { Acetylacetonatomanganese(II). } \\
\text { Dichlorobis(phenanthroline)manganese(II). }\end{array}$ & ST, MP, IR, XRD, & \\
\hline
\end{tabular}

*IR (infrared spectroscopy), XRD (X-ray diffraction), UV-Vis (ultraviolet-visible spectroscopy), MS (magnetic susceptibility), ST (solubility test), COD (chemical oxygen demand), VT (volumetric titration for elemental chemical analysis), MP (melting point), OM (optic microscopy), HW (hydration water determination), $\mathrm{Kj}$ (Kjeldahl analysis), IE (ionic exchange on resin).

contamination, synthesising compounds in minimum quantities, identifying compounds' possible environmental applications (i.e. as catalysts for environmental reactions) and separating and classifying chemical residues for subsequent treatments. In this point, it is important to take in mind that the science-technology-society (STS) movement constitutes both a paradigm shift and a mega-trend in science education that contributes to the goal of scientific literacy, and is a complex approach that integrates science contents into social and technological contexts meaningful to students. ${ }^{23}$

Figure 2 summarises the connections of main aspects and abilities to be developed through lab-projects in chemistry, or science, proposed by the author based on his experiences and students' evaluations. Figure 2 may be used as a guide for carrying out the laboratory activities by using mini-projects and IBL, which can be engaged in well form for obtaining interesting and positive results regarding science learning.

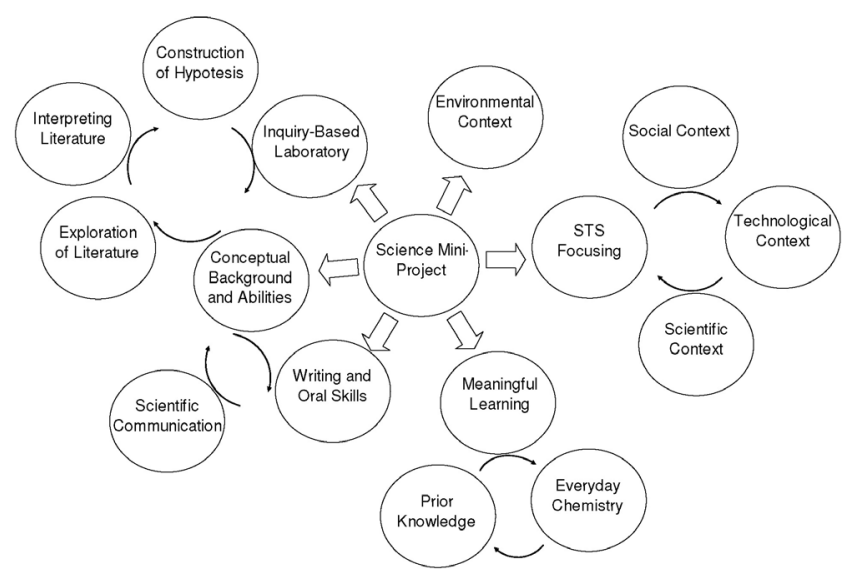

Figure 2. Aspects, abilities and contexts involved in carrying out science mini-projects in the chemistry laboratory
A real connection of different aspects mentioned in Figure 2 is only possible through a LP-IBL junction. The LP style is necessary to integrate all situations in lab activities at long time. Also, this period of time allows observing and evaluating students' progress about their contextualised science skills. Using IBL students would be aware of the process of producing, testing, and revising scientific knowledge. ${ }^{24}$ Science is, by its nature, an inquiry based discipline; and students are unable to fully appreciate the scientific methodologies and the essence of scientific inquiry unless they have the opportunity to acquire and analyse first-hand data. ${ }^{25}$ In the course of all learning activities of each mini-project a holistic view of language (listening, speaking, reading, writing) in science should be continuously constructed and evaluated, because a traditional segregation of this components can be frequently occur. ${ }^{26}$ For understanding and learning a contextualised science (with technological, social and environmental implication) an integrated view of language should be acquired, because students must explore and interpret scientific literature, verify social and environmental impacts of procedures and technological applications, and correctly communicate their results. Moreover, a symbolic (chemical) language is needed to construct chemical concepts, explain phenomena and perform calculations.

\section{CONCLUSIONS}

Laboratory projects (or mini-projects) can be used for carrying out inorganic chemistry laboratory activities by connecting them with IBL for obtaining better production of abilities and understanding synthesis procedures. This combination of methods led to students understanding the general principles of inorganic synthesis and characterisation techniques as well as developing several skills: cooperation attitudes and cooperative learning, literature exploration, hypothesis construction, writing and oral communication and associating environmental, technological, scientific and social contexts. Prior chemical knowledge as an important element of the meanin- 
gful learning model should be used; and a conceptual background with elementary experimental skills is required. However, teachers working in this experimental area must be committed and dynamic so as to be able to carefully review all mini-projects and engage in deep discussion of the proposed subjects with the students; this would involve frequently reading and following-up the scientific literature reported by the students.

\section{ACKNOWLEDGEMENTS}

The author would like to acknowledge the Universidad Nacional de Colombia (Bogotá) for facilitating the writing of this paper.

\section{REFERENCES}

1. Tytler, A.; Prain, V.; Int. J. Sci. Educ. 2010, 32, 2055.

2. Hofstein, A.; Chem. Educ. Res. Pract. 2004, 5, 247.

3. Mc Donnell, C.; O'Connor, C.; Seery, M.; Chem. Educ. Res. Pract. 2007, 8, 130.

4. Carriazo, J. C.; Khimiya/Chemistry. Bulg. J. Chem. Educ. 2010, 19, E103.

5. Reid, N.; Shah I.; Chem. Educ. Res. Pract. 2007, 8, 172.

6. Llorens-Molina, J. A.; Quim. Nova 2010, 33, 994.

7. Domin, D. S.; Chem. Educ. Res. Pract. 2007, 8, 140.

8. Petrosino, A. J.; J. Sci. Educ. Technol. 2004, 13, 447.
9. Mohrig, J. R.; Hammond, C. N.; Colby, D. A.; J. Chem. Educ. 2007, 84, 992.

10. Baldwin, M. J.; J. Chem. Educ. 2003, 80, 307.

11. Sanger, M. J.; J. Chem. Educ. 2008, 85, 297.

12. Pozo, J. I.; Gómez, M. A.; Aprender y enseñar ciencia. Del conocimiento cotidiano al conocimiento científico, ed. 3, Morata: Madrid, 2001.

13. Cakir, M.; Int. J. Environ. Sci. Educ. 2008, 3, 193.

14. Salta, K.; Tzougraki, C.; Res. Sci. Educ. 2010, in press: DOI 10.1007/ s11165-010-9181-6.

15. Morgan, K.; J. Chem. Educ. 2005, 82, 1178.

16. Cheung, D.; Int. J. Sci. Math. Educ. 2007, 6, 109.

17. Wu, H. K.; Wu, C. L.; Res. Sci. Educ. 2010, in press: DOI 10.1007/ s11165-010-9167-4.

18. King, D.; Bellocchi, A.; Ritchie, S. M.; Res. Sci. Educ. 2008, 38, 365.

19. Kovac, J.; Sherwood, D. W.; J. Chem. Educ. 1999, 76, 1399.

20. Widstrant, C. G.; Nordell, K. J.; Ellis, A. B.; J. Chem. Educ. 2001, 78, 1044.

21. Hailikari, T. K.; Nevgi A.; Int. J. Sci. Educ. 2010, 32, 2079.

22. Kaya, O. N.; Yager, R.; Dogan, A.; Res. Sci. Educ. 2009, 39, 257.

23. Lee, Y. Ch.; Int. J. Sci. Educ. 2010, 32, 1927.

24. Smith, C. L.; Maclin, D.; Houghton, C.; Hennessey, M. G.; Cognition Instruct. 2000, 18, 3349.

25. Sweeney, A. E.; Paradis, J. A.; Res. Sci. Educ. 2004, 34, 195.

26. Anthony, R. J.; Tippett, C. D.; Yore, L. D.; Res. Sci. Educ. 2010, 40, 45. 